\title{
Circulating monocytes from systemic sclerosis patients with interstitial lung disease show an enhanced profibrotic phenotype
}

\author{
Susan K Mathai ${ }^{1,4}$, Mridu Gulati ${ }^{1,4}$, Xueyan Peng ${ }^{1}$, Thomas R Russell ${ }^{1}$, Albert C Shaw ${ }^{1}$, Ami N Rubinowitz ${ }^{2}$, \\ Lynne A Murray ${ }^{3}$, Jonathan M Siner ${ }^{1}$, Danielle E Antin-Ozerkis ${ }^{1}$, Ruth R Montgomery ${ }^{1}$, Ronald AS Reilkoff ${ }^{1}$, \\ Richard J Bucala ${ }^{1}$ and Erica L Herzog ${ }^{1}$
}

Profibrotic cells derived from circulating CD14 + monocytes include fibrocytes and alternatively activated macrophages. These cells are associated with interstitial lung disease (ILD) and are implicated in the pathogenesis of systemic sclerosis (SSc); however, the simultaneous presence of profibrotic cells and their associated mediators in the circulation of these patients has not been defined. We hypothesized that monocytes from patients with SSc-related ILD (SSC-ILD) would show profibrotic characteristics when compared with normal controls. We recruited patients with SSC-ILD $(n=12)$ and normal controls $(n=27)$ and quantified circulating collagen-producing cells by flow cytometry for CD45 and pro-collagen I. The in vitro activation potential of CD14 + monocytes in response to lipopolysaccharide was assessed using flow cytometry for CD163, and by ELISA for CCL18 and IL-10 secretion. Profibrotic mediators in plasma were quantified using Luminexbased assays. The concentration of circulating collagen-producing cells was increased in the SSC-ILD patients when compared with controls. These cells were composed of both CD34 + fibrocytes and a population of CD34 + CD14 + cells. Cultured CD14 + monocytes from SSc-ILD patients revealed a profibrotic phenotype characterized by expression of CD163 and by enhanced secretion of CCL18 and IL-10 in response to proinflammatory activation. Plasma levels of IL-10, MCP-1, IL-1RA, and TNF levels were significantly elevated in the plasma of the SSc-ILD cohort. Subgroup analysis of the normal controls revealed that unlike the subjects $\leq 35$ years, subjects $\geq 60$ years old showed higher levels of circulating CD34 + CD14 + cells, collagen-producing CD14 + monocytes, CD163 + monocytes, IL-4, IL-10, IL-13, MCP-1, and CCL18. These data indicate that the blood of patients with SSc-ILD and of healthy aged controls is enriched for fibrocytes, profibrotic monocytes, and fibrosis-associated mediators. Investigations defining the factors responsible for this peripheral blood profile may provide new insight into SSc-ILD as well as the pathophysiology of aging.

Laboratory Investigation (2010) 90, 812-823; doi:10.1038/labinvest.2010.73; published online 19 April 2010

KEYWORDS: alternative activation; fibrocytes; macrophages; pulmonary fibrosis; scleroderma

Systemic sclerosis (SSc) or scleroderma is a multisystem autoimmune disease characterized by progressive cutaneous and visceral fibrosis. With advances in the treatment of SSc-related renal disease, pulmonary involvement has emerged as the greatest cause of mortality in SSc. ${ }^{1}$ The lungs of patients with SSc frequently show the pathological hallmarks of interstitial lung disease (SSc-ILD), with replacement of the normal lung architecture with inflamed and fibrotic tissue that is ineffective for gas exchange. Approximately $42 \%$ of patients with SSc-
ILD will die of disease progression within 10 years of diagnosis. ${ }^{1}$ Although treatment with cyclophosphamide has shown benefit in delaying disease progression, the overall clinical benefit is minor, and many patients relapse after treatment cessation. ${ }^{2}$ In addition, the prevalence of gastroesophageal reflux disease in these patients increases their risk for poor outcomes following lung transplantation. ${ }^{3,4}$ Thus, closer investigation of the pathogenesis of SSc-ILD has the potential to affect the proximate cause of death of most patients.

\footnotetext{
${ }^{1}$ Department of Internal Medicine, Yale University School of Medicine, New Haven, CT, USA; ${ }^{2}$ Department of Radiology, Yale University School of Medicine, New Haven, $\mathrm{CT}$, USA and ${ }^{3}$ Promedior, Inc, Malvern, PA, USA

Correspondence: Dr EL Herzog, MD, PhD, Department of Internal Medicine, Yale University School of Medicine, New Haven, CT 06511, USA. E-mail: erica.herzog@yale.edu

${ }^{4}$ These authors contributed equally to this work.

Received 12 October 2009; revised 13 January 2010; accepted 22 January 2010
} 
The CD14+ monocyte fraction of peripheral blood contains precursors to several mature cell lineages, including fibrocytes $^{5}$ and macrophages. ${ }^{6}$ Abnormalities of these cell types have been documented in scleroderma ${ }^{7-9}$ although their specific association with SSc-ILD is less well defined. Although all monocytes express CD14, these cells nevertheless exhibit considerable heterogeneity in terms of their differentiation and activation potential. ${ }^{6} \mathrm{CD} 14+$ monocyte precursors give rise to fibrocytes in animal models of renal fibrosis ${ }^{10}$ and in studies of cultured human peripheral blood cells. ${ }^{5}$ Fibrocytes are identified by their coexpression of the stem cell marker CD34, the leukocyte common antigen CD45, and extracellular matrix proteins such as collagen. ${ }^{11}$ An increasing amount of data highlight the association between elevated levels of peripheral blood fibrocytes and diverse forms of localized or diffuse organ remodeling such as renal fibrosis, ${ }^{12}$ cirrhosis, ${ }^{13}$ atherosclerosis, ${ }^{14}$ and nephrogenic systemic fibrosis. ${ }^{15}$ Multiple studies also demonstrate that elevated fibrocyte levels are found in the blood and in the lungs of patients with different types of pulmonary fibrosis. ${ }^{16-18}$ Although fibrocytes may be found in the skin lesions of patients with $\mathrm{SSc}^{19}$ and may have a role in the disease, a relationship between fibrocytes and SSc-ILD has not been investigated.

Most CD14 + monocytes differentiate into tissue macrophages, which can display distinct phenotypes of activation. ${ }^{20}$ In the lung, an important distinction is made along the lines of Th1 and Th2 inflammation. Th1, or 'classically' activated (M1), macrophages arise in response to priming with interferon- $\gamma($ IFN- $\gamma)$ or IL-1 and are identified by the expression of IL-12, TNF, and the chemokine CXCL10; these cells display a phenotype that is associated with tumor resistance, the destruction of intracellular parasites, and tissue damage. Th2, or 'alternatively' activated (M2), macrophages are derived following exposure to IL-4 or IL-13 and are identified in part by expression of the scavenger receptor CD163, the IL-1RII decoy receptor, mannose receptors, and by increased IL-10 and CCL18 production. ${ }^{21,22}$ Most of these markers are associated with such diverse diseases such as atopy, ${ }^{23}$ renal disease, and cirrhosis. ${ }^{24}$ CCL18 is a monocyte-derived chemokine that induces collagen production by fibroblasts; it is also strongly associated with lung fibrosis ${ }^{25}$ and has been shown recently to predict clinical outcomes in patients with $\mathrm{IPF}^{26}$ Stimulation of CD14 + cells with the bacterial cell wall component lipopolysaccharide (LPS) can induce an M1 or M2 phenotype depending on the activation potential of the precursor cell. ${ }^{23}$

Alveolar macrophages obtained from patients with SSc demonstrate a distinct $\mathrm{M} 2$ phenotype ${ }^{27}$ accompanied by high levels of CCL18 production. $^{26,28}$ However, there are scant data with regard to the alternative activation potential of monocytes derived from the peripheral blood of patients with this disease. Clarification of this concept could lead to the development of novel biomarkers to define disease activity and could provide novel targets for therapeutic intervention. On the basis of these considerations, we hypothesized that the peripheral blood of patients with SSc-ILD would contain monocytic precursors that are skewed toward the profibrotic phenotype of fibrocytes and alternatively activated macrophages. In addition, we undertook to define the soluble mediators associated with this cellular profile in the hope of gaining further insight into the factors promoting the development of ILD in patients with SSc.

\section{MATERIALS AND METHODS \\ Patients}

All studies were carried out with approval from the Human Investigations Committee at the Yale University School of Medicine. Patients followed at the Interstitial Lung Diseases Clinic at the Yale University School of Medicine were eligible to enroll. All patients were $>18$ years of age who had been diagnosed with SSc based on the American College of Rheumatology criteria and demonstrated ILD on high-resolution CT scan. Healthy, age-matched controls were recruited from the greater New Haven area. Exclusion criteria included current or recent use of immunosuppression, chronic infection such as HIV or hepatitis, known pulmonary hypertension, cardiovascular, renal or neoplastic disease, and inability to provide informed consent. Following enrollment and after giving informed consent, demographic data concerning age, race, sex, and comorbid conditions were collected on all subjects. In addition, data regarding restrictive ventilatory defect (decreased forced vital capacity) and diffusion impairment (decreased DLCO) were obtained from chart abstraction on the patients with SSc-ILD.

\section{Processing of Blood for Flow Cytometry}

Following informed consent and enrollment, $30 \mathrm{ml}$ of heparinized peripheral blood was drawn from study subjects, anonymized, and transported to the laboratory. The peripheral blood mononuclear cells (PBMCs) were isolated from the whole blood using Ficoll-paque-based separation (Stem Cell Technologies). Total viable cells were quantified using tryphan blue exclusion. Total blood fibrocyte levels and fibrocyte percentages were assessed using a minor modification of previously published protocols. ${ }^{29}$ Briefly, $10^{6}$ cells were suspended in $100 \mu \mathrm{l}$ of buffer and nonspecific antibody binding was minimized with $5 \mu \mathrm{l}$ of FcR-blocking agent (Miltenyi). Cells then were stained according to the manufacturer's instructions with $2 \mu \mathrm{l}$ of anti-CD45-PE (eBIoscience) or anti-CD45-PerCP (BD) antibodies, washed, and fixed with Cytofix/Cytoperm kit (BD Pharmingen) to permeabilize the cells. Cells were incubated with $1 \mu \mathrm{l}$ of ratanti-human pro-Col-I $\alpha$ antibody (Clone M58, Chemicon) or isotype control (Clone 43414, R\&D Systems), washed, and finally counter stained with goat-anti-rat FITC-labeled secondary antibody (Invitrogen) at 1:500 dilution. Nonspecific secondary antibody binding was further blocked with normal goat serum (10\% in the secondary antibody dilution). 


\section{CD14 + Monocyte Culture}

An aliquot of PBMCs separated from the freshly collected patient blood was enriched for CD14 + cells using MACS negative selection. Assessment of purity by flow cytometry for CD14 revealed that after one selection, cells were $>80 \%$ CD14 positive. A second purification procedure yielded a purity of $>90 \%$ (data not shown). Thus, the negative selection was performed twice. The remaining cells were plated into DMEM containing $10 \%$ fetal bovine serum $\pm 1 \mu \mathrm{g} / \mathrm{ml}$ LPS (Peprotech) as previously described. ${ }^{28}$ After $48 \mathrm{~h}$ of culture, cell morphology was assessed visually and the cells were harvested and stained for the alternatively activated macrophage phenotype and collagen production with antiCD163-PE (Dako) and anti-CD68-FITC (BD).

\section{Quantification of Leukocyte Subsets}

Total lymphocytes and monocytes were quantified on PBMCs using a flow cytometry assessment of forward-scatter $v s$ side-scatter characteristics. These percentages then were multiplied by total post-Ficoll cell counts to determine the total concentration of lymphocytes and monocytes per $\mathrm{ml}$ of blood.

\section{Flow Cytometry}

Flow cytometry was performed using a BD FACSCalibur. Data were analyzed using Flow Jo v 7.5 software (TreeStar).

\section{ELISA}

ELISA for CCL18, IL-10, and M-CSF were performed on plasma or culture supernatant according to the manufacturer's instructions (R\&D Systems). Multianalyte assessment on plasma was performed using Luminex technology as previously described. ${ }^{30}$

\section{Statistical Analysis}

Patients with SSc-ILD were compared with healthy controls. Continuous variables were analyzed using Student's $t$-test for normally distributed data and the Mann-Whitney $U$-test for data not normally distributed. Categorical variables were compared using $\chi^{2}$ or Fisher's exact test. Pearson's correlation coefficient was used to determine correlations between PBMC subsets and CD45/pro-Col-I $\alpha^{+}$cells. Exploratory analyses were conducted on the data from the control group in which data from younger and older subjects were compared. Significance was defined as $P<0.05$.

\section{RESULTS}

Subjects

Thirty-nine subjects were recruited for the initial studies. Of these, 27 were normal controls with no history of SSc-ILD. Twelve patients with SSc-ILD were recruited. Baseline characteristics of the studied groups are shown in Table 1. There was no difference between groups in terms of age, race, sex, history of hypertension, or hyperlipidemia. Although only three control subjects had a history of gastroesophageal reflux
Table 1 Characteristics of subjects

\begin{tabular}{lccc}
\hline Characteristic & Control $(n=27)$ & SSc-ILD $(n=12)$ & $P$-value \\
\hline Age (years) & $51.71 \pm 3.91$ & $47.42 \pm 3.13$ & 0.49 \\
Race-white & $21 / 27$ & $10 / 12$ & 0.39 \\
Sex-female & $16 / 27$ & $9 / 12$ & 0.79 \\
Hypertension & $8 / 27$ & $4 / 12$ & 0.42 \\
GERD & $3 / 27$ & $12 / 12$ & 0.03 \\
Hyperlipidemia & $4 / 27$ & $3 / 12$ & 0.78 \\
FVC, predicted percentage & $\mathrm{NA}$ & $64.58 \pm 3.44$ & $\mathrm{NA}$ \\
DLCO, predicted percentage & $\mathrm{NA}$ & $49.67 \pm 16.96$ & $\mathrm{NA}$ \\
\hline
\end{tabular}

Data are expressed as mean \pm s.e.m.

disease, all patients with SSc-ILD had a history of this disease $(P<0.03)$. Patients with SSc-ILD demonstrated a moderate restrictive ventilatory defect (forced vital capacity $=$ $64.58 \pm 3.44 \%$ ) and a severely impaired diffusion capacity $(\mathrm{DLCO}=49.67 \pm 16.96 \%)$. As control subjects self-identified as normal, no pulmonary testing is available for these subjects.

\section{Peripheral Blood CD45 ${ }^{+}$/pro-Col-I $\alpha^{+}$Cells Concentrations are Increased in SSC-ILD}

We first determined whether the blood of SSc-ILD patients was enriched for collagen-expressing cells using flow cytometry. Here, flow cytometry of PBMCs stained with CD45 and intracellular isotype control revealed a significant shift to the right. This control was used to set the negative gate for procollagen staining (Figure 1a) and isotype staining was subtracted from true-positive staining to determine the percentage of double-positive cells. This number then was multiplied by the total post-Ficoll PBMC count and divided by the input volume to determine concentrations of $\mathrm{CD} 45^{+}$/ pro-Col-I $\alpha^{+}$cells per ml.

Using this approach, we found a double-positive population of $\mathrm{CD}_{4} 5^{+} /$pro-Col-I $\alpha^{+}$monocytes in all subjects (Figure 1b-f). We did not detect a difference in the percentage of $\mathrm{CD} 45^{+} /$pro-Col-I $\alpha^{+}$cells (expressed relative to total PBMCs) between normal and SSc-ILD patients $(P<0.22$, Figure 1g, Table 2). However, there was a significant increase in the total number of $\mathrm{CD} 45^{+} /$pro-Col-I $\alpha^{+}$cells in the blood of SSc-ILD patients when compared with controls $(P<0.05$, Figure 1g). These cells displayed forward-scatter $v s$ side-scatter characteristics that gated to the monocyte fraction of PBMCs (Figure 1f, Table 2). These data indicate that PBMCs from patients with SSc-ILD are enriched for Col-I $\alpha$ production.

\section{Correlation of PBMC Subsets with CD45 ${ }^{+}$/pro-Col-l $\alpha^{+}$ Cells}

Subsets of PBMCs including lymphocytes and monocytes are both believed to be important for the appearance of 

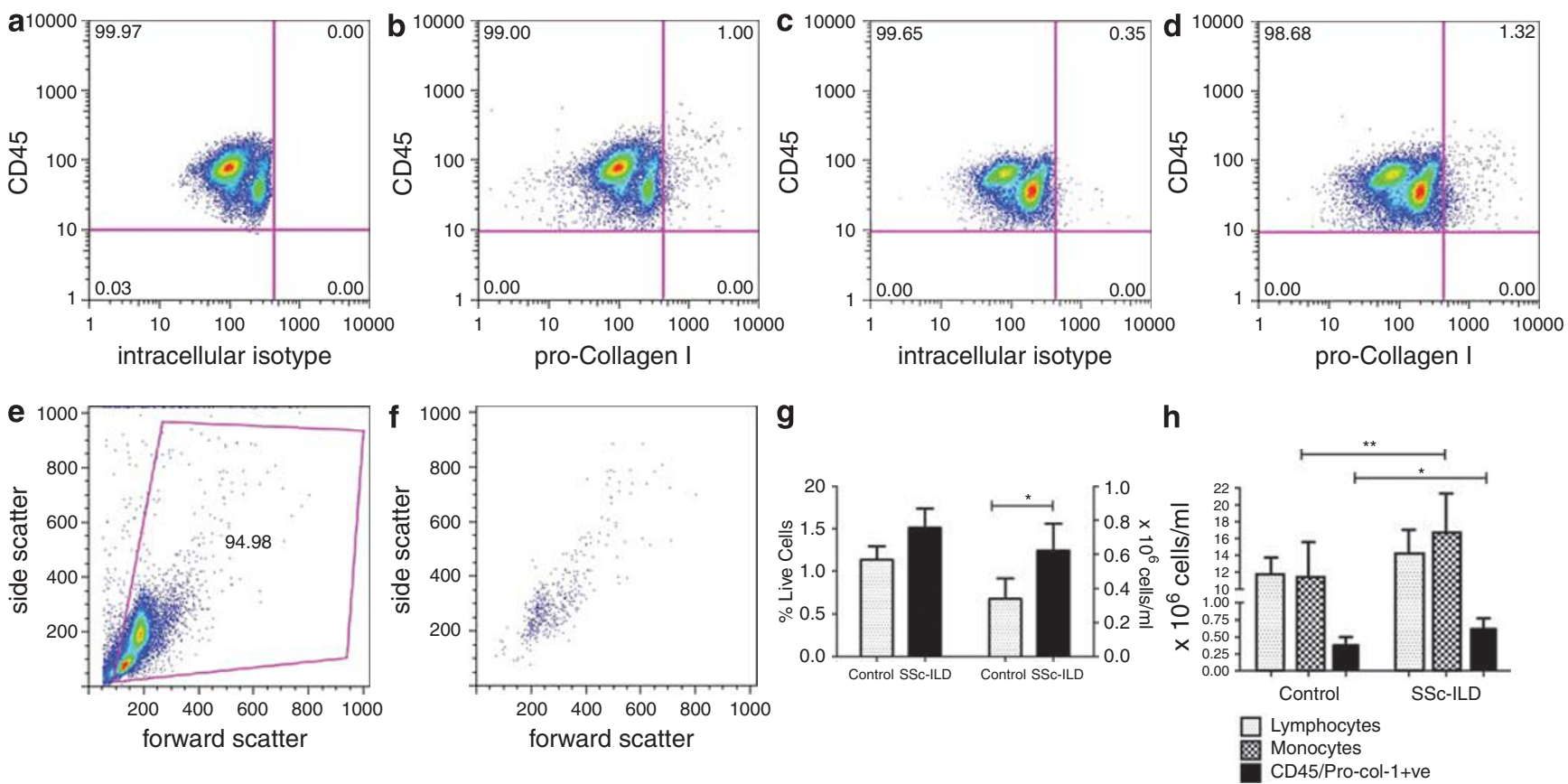

Figure $1 \mathrm{CD}^{2} 5^{+} /$pro-Col-I $\alpha^{+}$cells in SSc-ILD. (a) CD45-PE vs intracellular isotype control + anti-rat-FITC analyses on blood from a representative normal subject. This control was used to set negative gates. $x$ axis: rat lgGk intracellular isotype. $y$ axis: anti-CD45-PE. (b) $\mathrm{CD}_{4} 5^{+} / \mathrm{pro}-\mathrm{Col}-\mathrm{l} \alpha^{+}$cells in normal blood. $x$ axis: pro-Col-I $\alpha$ stained with anti-rat secondary antibody. $y$ axis: anti-CD45-PE. (c) Anti CD45-PE vs intracellular isotype control and anti-rat FITC carried out on blood from patient with SSc-ILD. This control was used to set negative gates for the SSc-ILD sample. $x$ axis: rat IgGk intracellular isotype. $y$ axis: anti-CD45PE. (d) CD45 ${ }^{+} /$pro-Col-l $\alpha^{+}$cells in SSc-ILD blood, same axes as panel b. (e) FSC vs SSC analysis of PBMCs from the sample in (d). (f) FSC vs SSC analysis of PBMCs from the double-positive population in (d). (g) Comparison of $\mathrm{CD} 45^{+} / \mathrm{pro}-\mathrm{Col}-\mathrm{l} \alpha^{+}$percentages (left axis) and quantities (right axis) in normal ( $n=27$, gray bar) and SSc-ILD subjects ( $n=12$, black bar). CD45 ${ }^{+} /$pro-Col-l $\alpha^{+}$cells quantities, but not percentages, are increased in SSc-ILD. (h) Comparison of lymphocytes (dotted bar), monocytes (checked bar), and CD45 ${ }^{+} /$pro-Col-l $\alpha^{+}$(black bar) concentrations in normal control (left) and SSc-ILD blood (right). Monocyte quantities are increased in patients with SSc-ILD. Data are expressed as mean \pm s.e.m. ${ }^{*} P<0.05,{ }^{*} P<0.01$.

Table $2 \mathrm{CD}^{+} 5^{+} /$pro-Col-I ${ }^{+}$cells percentages in peripheral blood and CCL18 and IL-10 levels in culture supernatant (control vs SSc-ILD)

\begin{tabular}{|c|c|c|c|}
\hline & Control $(n=27)$ & SSC-ILD $(n=12)$ & $P$-value \\
\hline $\begin{array}{l}\mathrm{CD} 45^{+} / \text {pro-Col-l } \alpha^{+} \text {cells } \\
\text { percentage }\end{array}$ & $1.13 \pm 0.16$ & $1.34 \pm 0.25$ & 0.22 \\
\hline $\begin{array}{l}\mathrm{CD} 45^{+} / \text {pro-Col-I } \alpha^{+} \text {cells } \\
\text { number }\left(\times 10^{6}\right)\end{array}$ & $0.34 \pm 0.12$ & $0.61 \pm 0.160$ & 0.031 \\
\hline -LPS, \% CD163+ & $5.817 \pm 1.88$ & $7.812 \pm 2.120$ & 0.21 \\
\hline +LPS, \% CD163+ & $7.91 \pm 1.805$ & $11.16 \pm 1.500$ & 0.19 \\
\hline -LPS, CCL18 (pg/ml) & $67.08 \pm 26.43$ & $172.1 \pm 143.9$ & 0.6 \\
\hline +LPS, CCL18 (pg/ml) & $156.4 \pm 44.09$ & $703.6 \pm 159.3$ & 0.0009 \\
\hline -LPS, IL-10 (pg/ml) & $209.6 \pm 56.95$ & $58.42 \pm 20.92$ & 0.03 \\
\hline +LPS, IL-10 (pg/ml) & $370.2 \pm 71.29$ & $1388 \pm 256.6$ & 0.04 \\
\hline
\end{tabular}

collagen-producing cells in the peripheral blood. ${ }^{31,32}$ To explore this concept further, we quantified the numbers of lymphocytes and monocytes in the blood of SSc-ILD patients and normal controls and determined whether either or both of these cell types correlate with the $\mathrm{CD} 45^{+} /$pro-Col-I $\alpha^{+}$ cells. We found an increase in circulating monocytes in the blood of patients with SSc-ILD (Figure 1h). This increase in monocytes approached a moderate correlation with $\mathrm{CD} 45^{+} /$ pro-Col-I $\alpha^{+}$cells ( $r$ value $\left.0.58, P=0.06\right)$. Although we did not observe an increase in the absolute number of circulating lymphocytes in patients with SSc-ILD $v s$ normal controls, there was a strong and significant correlation between lymphocytes and $\mathrm{CD} 45^{+} /$pro-Col-I $\alpha^{+}$cells in the blood of patients with SSc-ILD ( $r$ value $0.64, P<0.03$ ). In contrast, monocytes displayed a very strong association with $\mathrm{CD} 45^{+}$/ pro-Col-I $\alpha^{+}$cells in the control population ( $r$ value 0.86 , $P<0.0001)$ and there was no association between lymphocytes and $\mathrm{CD} 45^{+}$pro-Col- $\mathrm{I}^{+}$cells in the controls ( $r$ value $0.21, P=0.27)$. These data indicate that lymphocytes, but not monocytes, correlate with the increase in $\mathrm{CD}_{4} 5^{+}$/ pro-Col-I $\alpha^{+}$cells in patients with SSc-ILD.

\section{SSc-ILD Monocytes Increase CD163 Expression in Response to LPS}

The expression of CD163 signifies the alternatively activated macrophage, and this marker has been used previously to enumerate this macrophage sub-population in a number of pathological conditions including pulmonary fibrosis and SSc-ILD. ${ }^{33,34}$ CD163 + expression in response to LPS stimulation also has been reported to identify $\mathrm{CD} 14+$ cells that are skewed toward alternative activation in response to LPS 
a
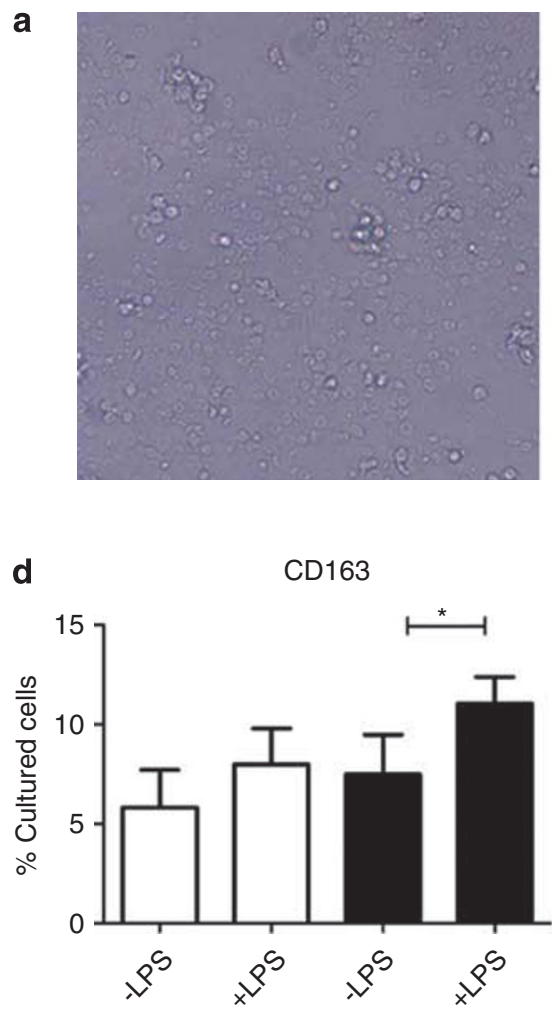

b

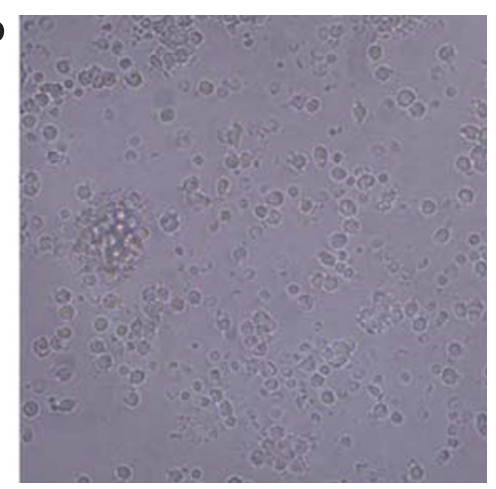

e

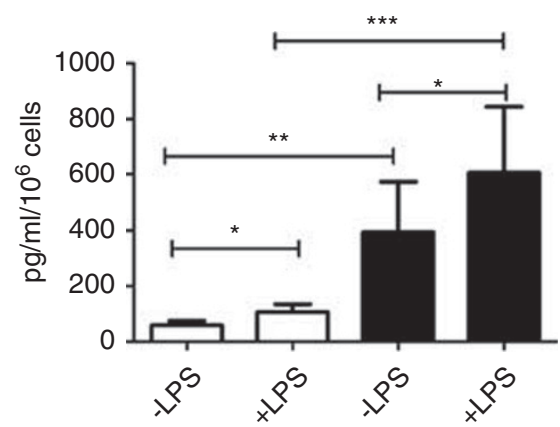

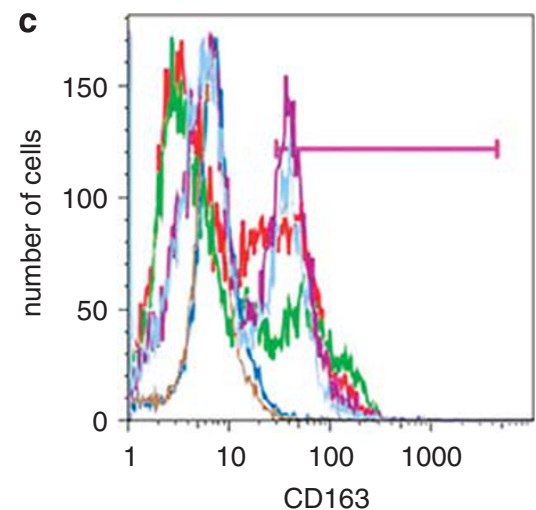

f

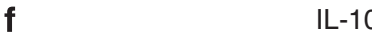

Figure 2 Alternative macrophage activation in SSc-ILD. (a, b) Light microscopy of CD14 + peripheral blood monocytes that were cultured in the absence (a) and presence (b) of LPS. (c) Overlay of histograms of CD163 staining on cultured CD14 + monocytes. Brown: young control, no LPS. Dark blue: young control, + LPS. Green: aged control, no LPS. Red: aged control, + LPS. Light blue: SSc-ILD, no LPS. Purple: SSc-ILD, + LPS. The pink bar indicates the positive gate. (d) Percentage of CD14 + cells that express CD163 following $48 \mathrm{~h}$ in culture. White bar: control; black bar: SSc-ILD. (e) CCL18 secretion following $48 \mathrm{~h}$ in culture. White bar: control; black bar: SSc-ILD. ${ }^{\star} P<0.05,{ }^{* *} P<0.01,{ }^{* *} P<0.001$. (f) IL-10 secretion following $48 \mathrm{~h}$ in culture. White bar: control ( $\left.n=27\right)$. Black bar: SSc-ILD $(n=12) .{ }^{\star} P<0.05,{ }^{* *} P<0.01,{ }^{* *} P<0.001$. All data are expressed as mean \pm s.e.m.

stimulation in the blood of patients with atopy. ${ }^{23}$ CD163 expression is also enhanced in the lungs of patients with many types of pulmonary fibrosis, ${ }^{26}$ hence we expected that the blood of patients with SSc-ILD would show increased CD163 expression in response to LPS stimulation when compared with normal controls.

As CD163 has recently been reported to be expressed on cultured fibrocytes, ${ }^{35}$ we first assessed cultured cells for the characteristic spindle-shaped morphology of fibrocytes. We found that $\mathrm{CD} 14+$ monocytes maintained a rounded morphology after $48 \mathrm{~h}$ in culture and that no cells showed the spindle-shaped morphology of fibrocytes (Figure 2a and b). These data indicate that cells expressing CD163 in this system are unlikely to be mature fibrocytes. We next performed flow cytometry on these cultured cells. Our results showed that unstimulated $\mathrm{CD} 14+$ monocytes from control subjects displayed different levels of CD163 expression. LPS stimulation increased CD163 expression by $47.5 \%$ in the patients with SSc-ILD but had no effect on its expression in the control population (Table 2, Figure $2 \mathrm{c}$ and d). Monocytes from some controls displayed very little CD163 expression, whereas monocytes from other controls showed very high expression of this receptor (Figure 2c). These data indicate that $\mathrm{CD} 14+$ monocyte $\mathrm{CD} 163$ expression is differentially influenced by LPS activation in the SSc-ILD patients.

\section{LPS-Stimulated CCL18 and IL-10 Secretion by Monocytes is Enhanced in SSC-ILD}

We next assessed functional differences in monocytes obtained from these patients. CCL18 is a monocyte-derived chemokine that induces T-cell migration and collagen production by fibroblasts. CCL18 is elevated in the lungs of patients with SSc-ILD and is a biomarker of disease progression in patients with IPF. We found a substantial increase in both baseline and LPS-stimulated CCL18 production in the SSc-ILD monocytes compared with normal controls $(P<0.01$ and $<0.001$ respectively, Figure $2 e$, Table 2$)$. As IL10 has been shown to promote CCL18 production in human cells $^{26,36}$ and perpetuate fibrosis in murine models, ${ }^{37}$ we measured this cytokine as well. Unstimulated monocytes obtained from both normal controls and SSc-ILD patients produced equivalent levels of IL-10; however, LPS stimulation of monocytes from patients with SSc-ILD produced nearly triple the amount of IL-10 as those from normal controls (Figure 2f, Table 2). These data suggest that nonspecific stimulation with LPS induces a profibrotic phenotype in monocytes from patients with SSc-ILD. 

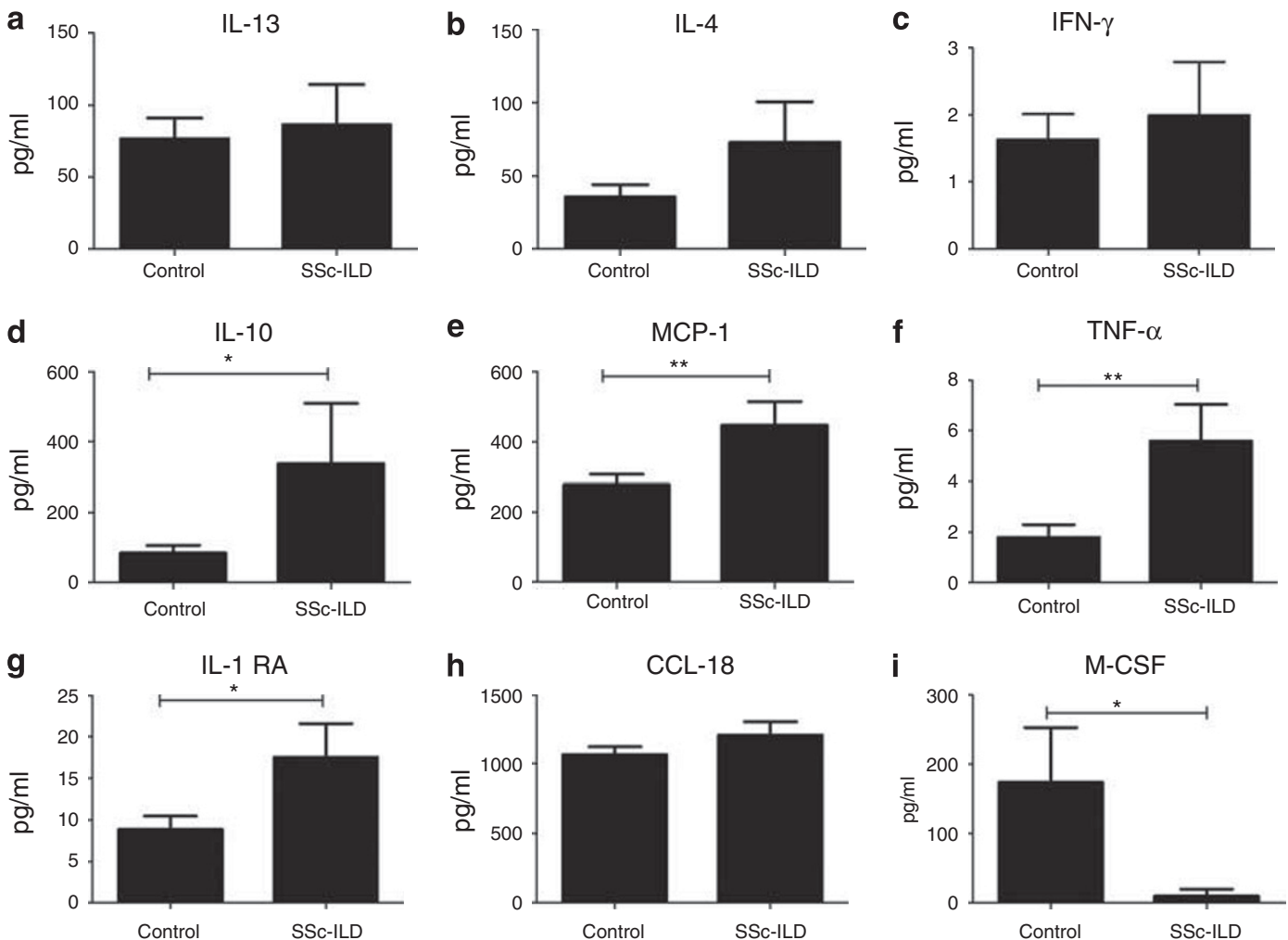

Figure 3 Multianalyte ELISA comparisons of plasma cytokines in control $(n=27$, left) vs SSc-ILD subjects $(n=11$, right). (a) IL-13. (b) IL-4. (c) IFN- $\gamma$. (d) IL-10.

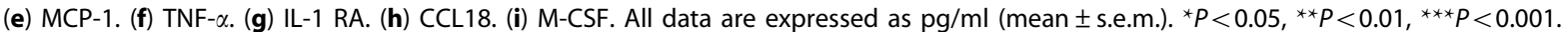

\section{Multianalyte ELISA Analysis of SSc-ILD Patient Plasma Reveals an Increase in Profibrotic Mediators}

To gain a better understanding of the soluble factors associated with a fibrogenic monocyte phenotype, we performed multianalyte ELISA on plasma samples obtained from the SSc-ILD patient and control groups. Owing to the increased number of $\mathrm{CD}_{4} 5^{+} /$pro-Col- $\mathrm{L}^{+}$cells and the alternative activation of LPS-stimulated monocytes found in SSc-ILD patients, we expected to find an increase in Th2 cytokines (which promote fibrocyte differentiation and M2 activation) and decreased Th1 cytokines (which inhibit these processes). It is interesting that neither the circulating levels of the Th2 cytokines, IL-13 and IL-4, or the Th1 cytokine, IFN- $\gamma$, differed between the two groups (Figure $3 \mathrm{a}-\mathrm{c}$ ). We found significantly higher levels of IL-10 $(P<0.04$, Figure $3 \mathrm{~d})$, the chemokine MCP-1 $(P<0.01$, Figure 3e), which affects the trafficking of both fibrocytes and monocytes, TNF- $\alpha$, which can both promote and suppress fibrosis $(P<0.01$, Figure $3 \mathrm{f})$, and IL-1RA $(P<0.02$, Figure $3 \mathrm{~g})$, whose function is to suppress inflammation. CCL18 levels did not differ between these groups (Figure $3 \mathrm{~h}$ ). In addition, M-CSF, which induces the development of macrophages from $\mathrm{CD} 34+$ hematopoietic stem cells, was significantly reduced in patients with SSc-ILD compared with normal controls $(P<0.05$, Figure 3i). These data are also shown in Table 3.
Table 3 Plasma cytokine levels (control vs SSc-ILD)

\begin{tabular}{lccc}
\hline & Control $(n=27)$ & SSc-ILD $(n=11)$ & $P$-value \\
\hline MCP-1 $(\mathrm{pg} / \mathrm{ml})$ & $300.2 \pm 43.25$ & $557.7 \pm 96.08$ & 0.01 \\
IL-13 $(\mathrm{pg} / \mathrm{ml})$ & $120.9 \pm 12.95$ & $119.5 \pm 30.77$ & 0.925 \\
$\mathrm{IL}-4(\mathrm{pg} / \mathrm{ml})$ & $59.90 \pm 13.25$ & $72.48 \pm 27.94$ & 0.62 \\
$\mathrm{IFN}-\gamma(\mathrm{pg} / \mathrm{ml})$ & $1.710 \pm 0.830$ & $1.991 \pm 0.811$ & 0.87 \\
$\mathrm{TNF}-\alpha(\mathrm{pg} / \mathrm{ml})$ & $3.400 \pm 0.750$ & $5.581 \pm 1.467$ & 0.01 \\
$\mathrm{IL}-1 \mathrm{RA}(\mathrm{pg} / \mathrm{ml})$ & $111.2 \pm 18.72$ & $382.8 \pm 165.4$ & 0.02 \\
$\mathrm{IL}-10(\mathrm{pg} / \mathrm{ml})$ & $8.850 \pm 1.164$ & $18.94 \pm 3.495$ & 0.04 \\
$\mathrm{CCCL} 18(\mathrm{pg} / \mathrm{ml})$ & $1067 \pm 56.01$ & $1209 \pm 96.25$ & 0.21 \\
$\mathrm{M}-\mathrm{CSF}(\mathrm{pg} / \mathrm{ml})$ & $174.0 \pm 78.80$ & $9.971 \pm 8.234$ & 0.05 \\
\hline
\end{tabular}

\section{Subgroup Analysis of Control Group Blood}

Further analysis of the data from control samples revealed an unexpected age-dependent pattern; when compared with the younger controls $(n=10)$, blood from older controls $(n=12)$ showed a higher percentage and quantity of circulating $\mathrm{CD}_{4} 5^{+} /$pro-Col-I $\alpha^{+}$cells (Figure $4 \mathrm{a}-\mathrm{e}$, Table 4 ) and PBMCs, which contained increased lymphocytes and monocytes than the younger patients (Figure 4f Table 4). 

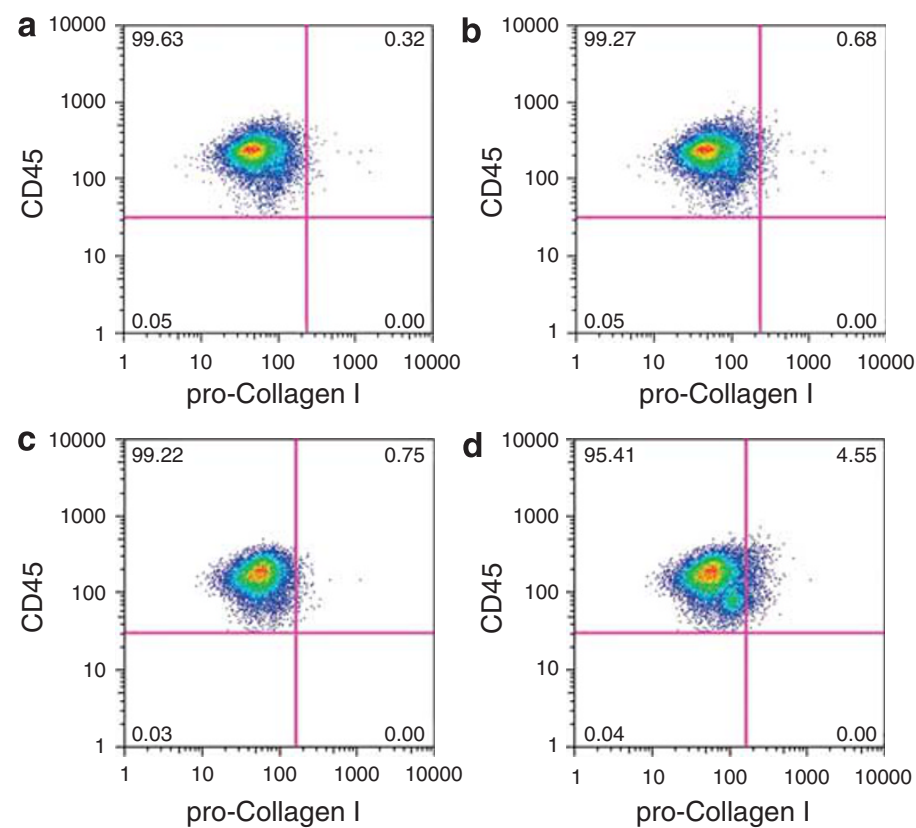

g

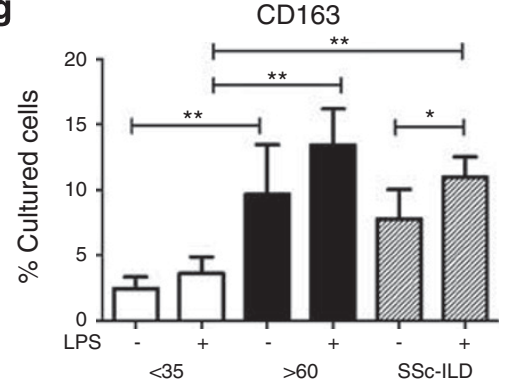

j

IL-13

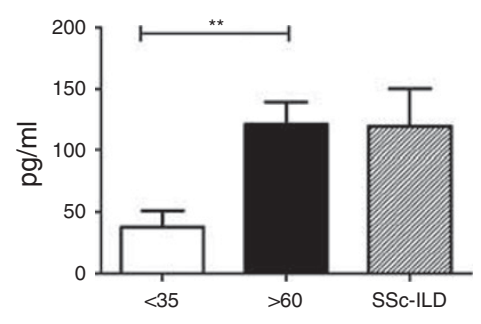

m

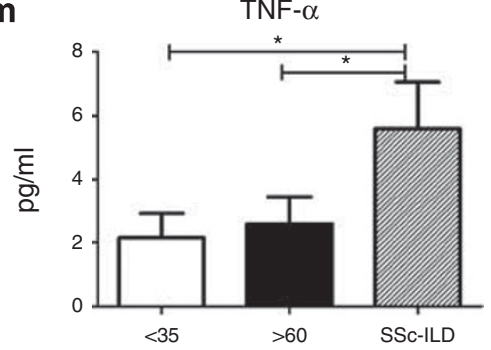

h

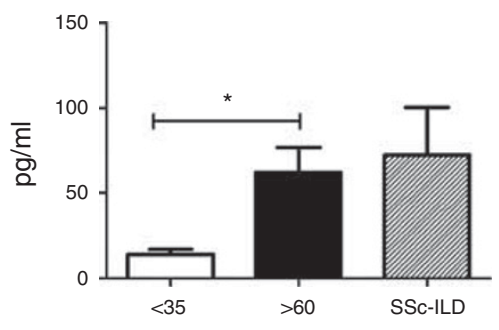

k

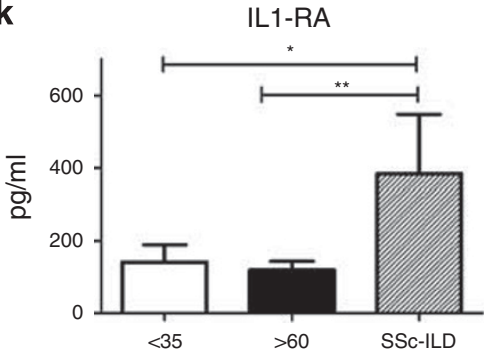

n

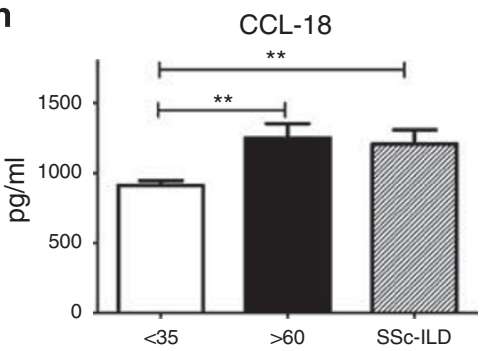

e
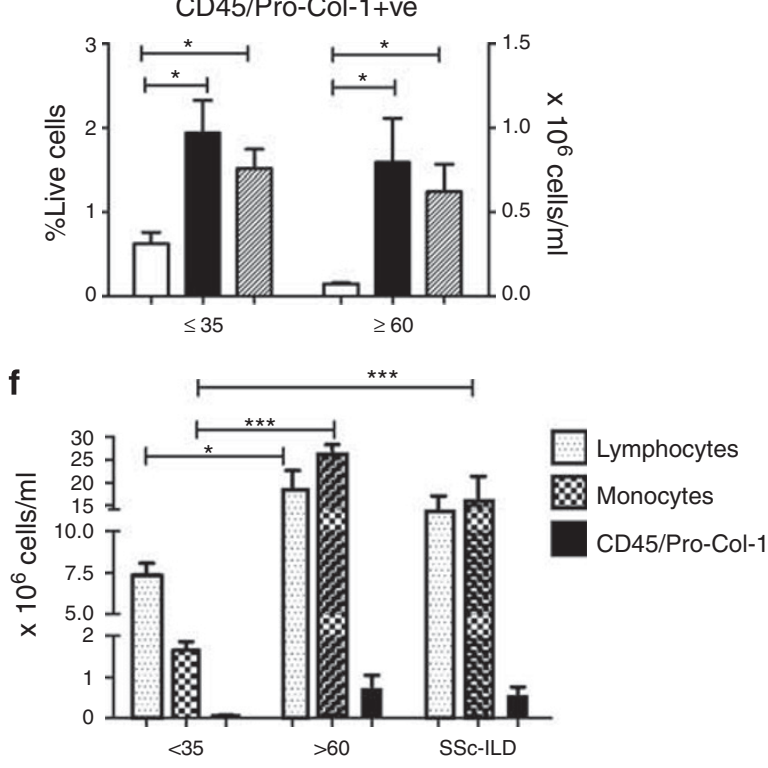

i
I

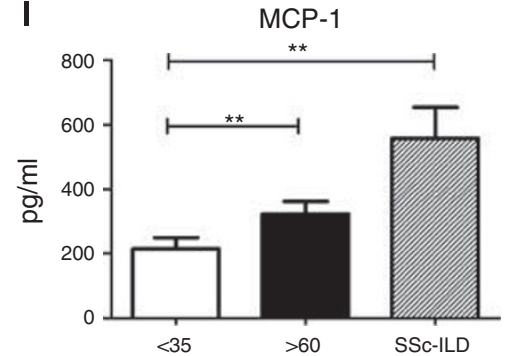

o

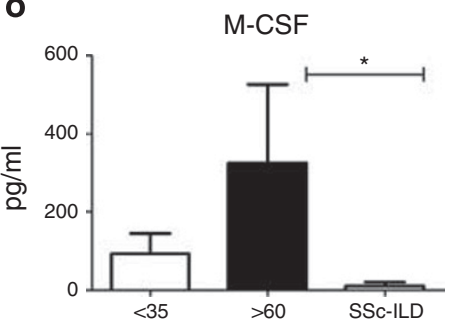

Figure 4 Subgroup analysis of peripheral blood monocyte subpopulations and fibrogenic mediators in young vs aged controls. (a) Staining with anti-CD45$\mathrm{PE}$ vs intracellular isotype control antibody used to set negative gates. (b) $\mathrm{CD} 45^{+} /$pro-Col-l $\alpha^{+}$staining (CD45-PE vs pro-Col-l $\alpha$ ) in young healthy control. (c) Anti-CD45-PE vs intracellular isotype control antibody used to set negative gates. (d) $\mathrm{CD}_{4} 5^{+} /$pro-Col-l $\alpha^{+}$staining (CD45-PE vs pro-Col-l $\alpha$ ) in aged healthy control. (e) $\mathrm{CD}_{4}{ }^{+} /$pro-Col-l $\alpha^{+}$percentages (left axis) and quantities (right axis) in young subjects (white bar), aged subjects (black bar), and SSc-ILD patients (slanted lines). (f) Comparison of lymphocytes (dotted line), monocytes (checked bar), and CD45 ${ }^{+} /$pro-Col-l $\alpha^{+}$cells (black bar) in (left to right) young, aged, and SSC-ILD subjects. (g) CD14 + monocyte expression of CD163 after $48 \mathrm{~h}$ in culture. (h-o) Concentrations of the plasma cytokines IL-4 (h), IL-10 (i), IL-13 (j), IL-1 RA (k), MCP-1 (I), TNF- $\alpha(\mathbf{m})$, CCL18 (n), and M-CSF (o) in young controls $(n=10$, white bar), aged controls $(n=12$, black bar), and patients with SSC-ILD ( $n=11$, slanted bar). All data are expressed as mean \pm s.e.m. ${ }^{\star} P<0.05,{ }^{* *} P<0.01,{ }^{* * *} P<0.001$. 


\begin{tabular}{|c|c|c|c|}
\hline & $\begin{array}{c}<35 \text { years } \\
(n=10)\end{array}$ & $\begin{array}{c}>60 \text { years } \\
(n=12)\end{array}$ & $P$-value \\
\hline $\begin{array}{l}\mathrm{CD} 5^{+} / \text {pro-Col-l } \alpha^{+} \text {cells } \\
\text { percentage }\end{array}$ & $0.620 \pm 0.014$ & $1.932 \pm 0.3900$ & 0.001 \\
\hline $\begin{array}{l}\mathrm{CD} 45^{+} / \text {pro-Col-l } \alpha^{+} \text {cells } \\
\text { concentration }\end{array}$ & $0.070 \pm 0.010$ & $0.790 \pm 0.265$ & 0.007 \\
\hline Lymphocyte concentration & $7.380 \pm 0.680$ & $18.31 \pm 4.310$ & 0.03 \\
\hline Monocyte concentration & $1.661 \pm 0.221$ & $27.06 \pm 1.312$ & 0.0001 \\
\hline -LPS, \% CD163+ & $2.465 \pm 0.900$ & $9.724 \pm 3.744$ & 0.02 \\
\hline +LPS, \% CD163+ & $3.632 \pm 1.261$ & $13.42 \pm 2.766$ & 0.01 \\
\hline IL-4 (pg/ml) & $14.22 \pm 2.99$ & $62.47 \pm 14.51$ & 0.003 \\
\hline IL-10 (pg/ml) & $4.169 \pm 1.285$ & $12.10 \pm 1.88$ & 0.004 \\
\hline IL-13 (pg/ml) & $37.71 \pm 13.27$ & $121.2 \pm 18.41$ & 0.004 \\
\hline IL-1RA (pg/ml) & $140.7 \pm 48.76$ & $118.6 \pm 25.16$ & 0.04 \\
\hline MCP-1 (pg/ml) & $214.8 \pm 34.59$ & $322.5 \pm 39.84$ & 0.05 \\
\hline TNF- $\alpha(\mathrm{pg} / \mathrm{ml})$ & $2.158 \pm 0.76$ & $2.591 \pm 0.852$ & 0.70 \\
\hline CCL-18 (pg/ml) & $913.3 \pm 33.92$ & $1251 \pm 102.1$ & 0.01 \\
\hline $\mathrm{M}-\mathrm{CSF}(\mathrm{pg} / \mathrm{ml})$ & $93.02 \pm 51.60$ & $324.5 \pm 201.6$ & 0.42 \\
\hline
\end{tabular}

$\mathrm{CD} 45^{+} /$pro-Col-I $\alpha^{+}$cells and total monocytes were very strongly correlated in the older subjects ( $r$ value 0.81 , $P<0.00016)$, whereas no correlation existed between these cell types in the younger subjects ( $r$ value $0.35, P=0.24$ ). There was no association with lymphocytes in either of these populations (data not shown). In addition, there was an increase in both baseline and LPS-stimulated CD163 expression on monocytes obtained from the older individuals (Figure $4 \mathrm{~g}$ ). Although there was no difference in baseline or LPS-stimulated CCL18 or IL-10 secretion (data not shown), we did observe increased circulating IL-4 $(P<0.03)$, IL-10 $(P<0.004)$, IL-13 $(P<0.004)$, MCP-1 $(P<0.05)$, and CCL18 $(P<0.01)$ in the older controls. TNF- $\alpha$ and IFN- $\gamma$ did not differ between these groups (Table 4 and Figure $4 \mathrm{~h}-\mathrm{o}$ ). This analysis also demonstrated that concentrations of CCL18, IL-10 and MCP-1 were elevated in SSc-ILD when compared with the young controls $(P<0.01$ for all comparisons, Figure $4 \mathrm{i}$, $\mathrm{n}$, and $\mathrm{l})$. IL-4 and IL-13 in the SSc-ILD patients did not differ from either the young or old subsets (Figure $4 \mathrm{~h}$ and $\mathrm{j}$ ). IL-1RA and TNF- $\alpha$ were elevated in the SSc-ILD patients when compared with both young and older subjects $(P<0.05$ for all comparisons, Figure $4 \mathrm{j}$ and $\mathrm{k}$ ). Interestingly, M-CSF was lower in the SSc-ILD patients than in the aged controls $(P<0.05$, Figure $4 \mathrm{o})$. These data are the first to suggest that the blood of healthy, but aged controls, displays a distinct profibrotic signature that is unique from that of SSc-ILD patients.

\section{Variable Phenotype of $\mathrm{CD}^{+} 5^{+} /$pro-Col-l $\alpha^{+}$Cells in SSc-ILD vs Aged Controls}

As we found differences in the circulating factors that accompany increased $\mathrm{CD} 45^{+} /$pro-Col- $\alpha^{+}$cells in the blood of healthy aged controls compared with that of patients with SSc-ILD, we sought to more accurately phenotype the $\mathrm{CD} 45^{+} /$pro-Col- $\alpha^{+}$cells found in the blood of these individuals. Accordingly, we recruited an additional seven patients with SSc-ILD and ten aged controls and repeated the $\mathrm{CD} 45^{+} /$pro-Col-I $\alpha^{+}$analysis with the addition of two additional markers, CD14 and CD34. These cell surface markers were selected to determine whether monocytes or fibrocytes accounted for the increase in circulating collagen-producing cells. Our initial results confirmed our previous studies, showing that both these groups contained elevated numbers of $\mathrm{CD} 45^{+} /$pro-Col- $\mathrm{I} \alpha^{+}$cells expressing cells in the circulation (data not shown). When we gated on this dual-positive population and quantified CD14 and CD34 expression, we found that the collagen I-expressing cells in all subjects expressed CD14 and CD34 to varying degrees (Figure 5a-f). In the patients with SSc-ILD, the collagen-expressing cells were primarily $\mathrm{CD} 34^{+}(32.31 \pm 7.432 \%$ vs $6.134 \pm 3.641 \%$, $P<0.004$, Figure $5 \mathrm{~g})$ or $\mathrm{CD} 34^{+} \mathrm{CD} 14+(35.01 \pm 11.34 \%$ vs $17.26 \pm 4.072 \%, P=0.18$, Figure 5 h). In contrast, $\mathrm{CD} 45^{+}$, pro-Col-I $\alpha^{+}$cells from the aged patients were enriched for CD14 expression $(44.96 \pm 7.18 \%$ vs $10.98 \pm 6.712, P<0.01$, Figure 5i) as well as for a population of cells that expressed neither marker $(30.44 \pm 7.814 \%$ vs $11.35 \pm 4.412 \%, P<0.05$, Figure 5j). These results demonstrate that different cell populations account for the increase in collagen-producing cells found in the circulation of subjects with SSc-ILD and in that of healthy aged controls.

\section{DISCUSSION}

Our data show that monocytes obtained from the blood of patients with SSc-ILD display a fibrogenic phenotype. Specifically, the blood of patients with SSc-ILD shows increased numbers of fibrocytes and collagen-producing monocytes when compared with healthy age-matched controls. In addition, LPS stimulation of CD14 + monocytes from these patients led to substantially increased expression of CD163 and the profibrotic mediators, CCL18 and IL-10. In addition, blood of patients with SSc-ILD contained significantly higher concentrations of IL-10, MCP-1, TNF- $\alpha$, and IL-1 RA. Lastly, the blood of aged healthy controls contained increased quantities of collagen-producing monocytes, an increase in CD163-expressing monocytes, and higher circulating levels of CCL18, IL-4, IL-10, IL-13, and MCP-1 when compared with younger individuals. These data provide new information with regard to the relationship between fibrogenic monocyte precursors, SSc-ILD, and normal aging.

Circulating cells that express collagen I are associated with an expanding repertoire of human diseases including renal fibrosis, ${ }^{12}$ cirrhosis, ${ }^{13}$ scleroderma, ${ }^{7}$ nephrogenic systemic 


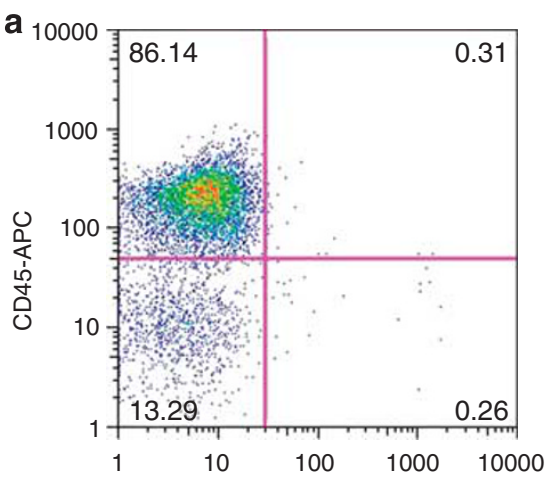

FL3 - isotype control

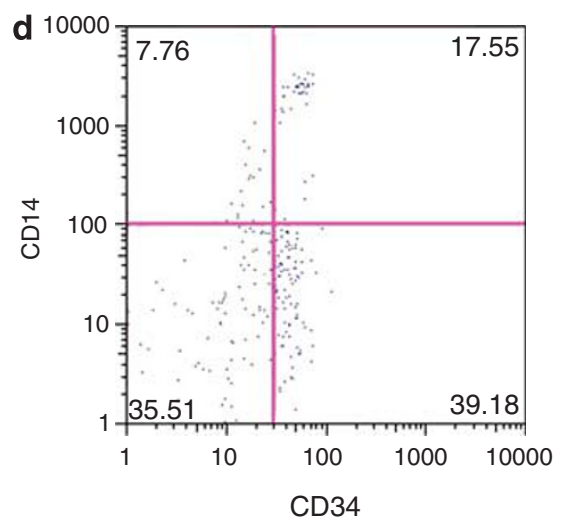

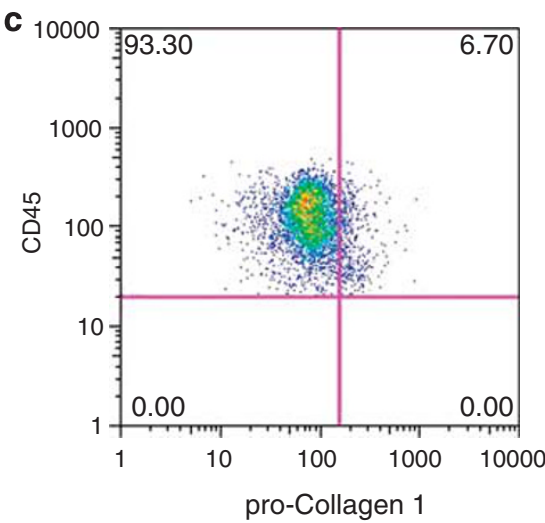
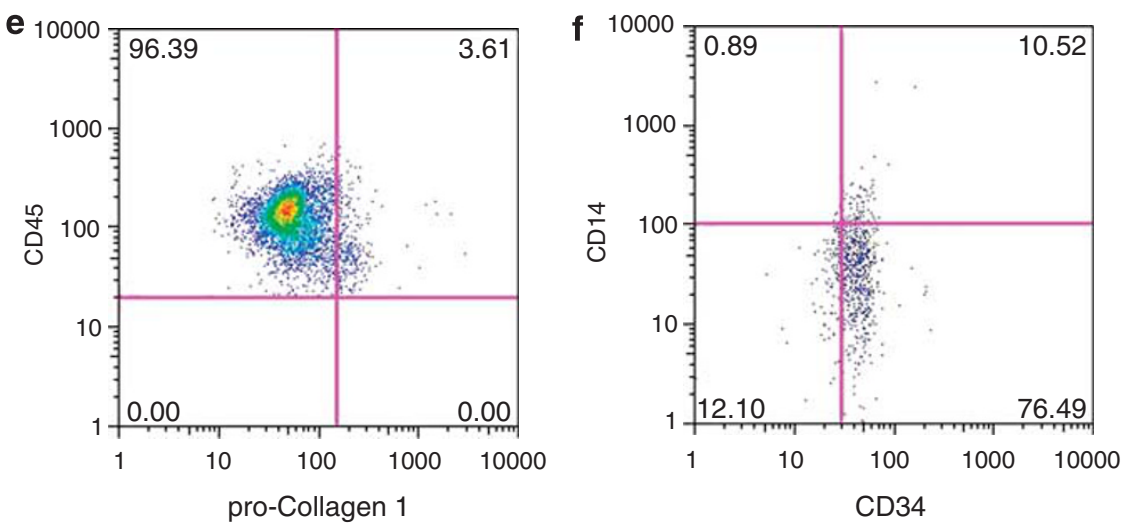

g

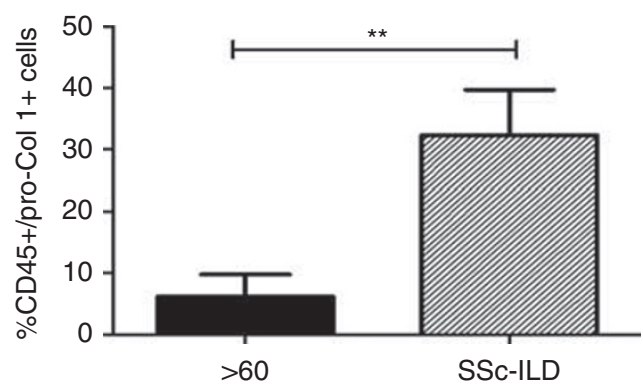

i

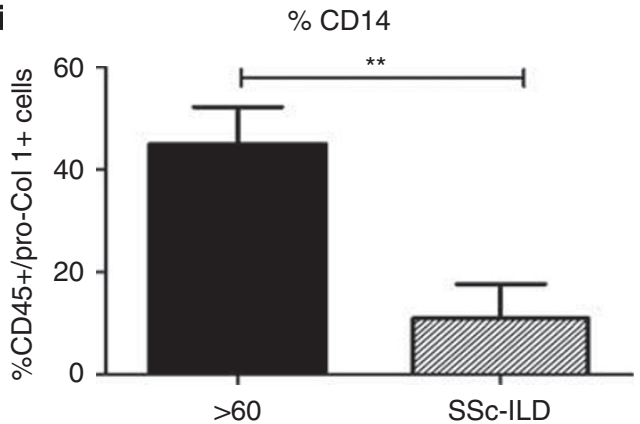

$\mathbf{h}$

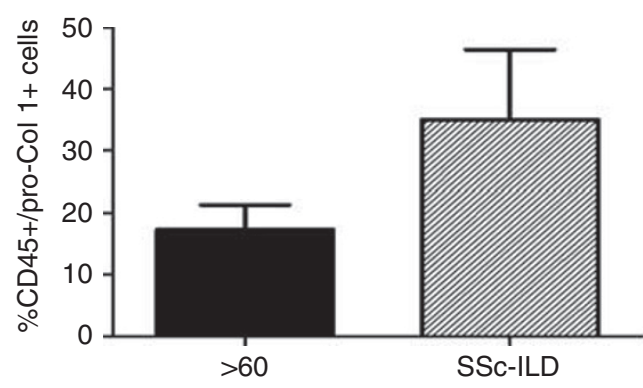

j Neither

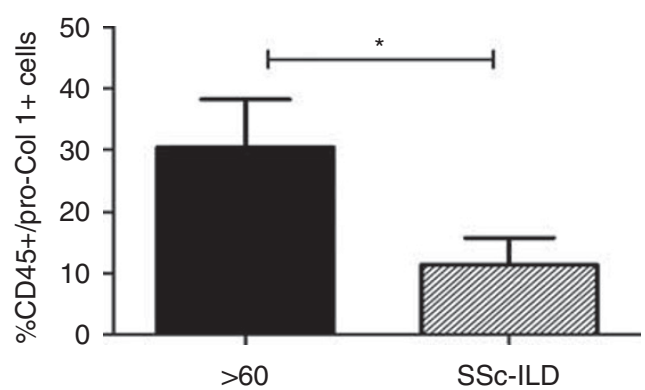

Figure 5 Phenotype of $\mathrm{CD} 45^{+} /$pro-Col-I $\alpha^{+}$cells in SSc-ILD and aged, healthy controls. (a) PerCP isotype control ( $x$ axis) vs Anti-CD45-APC (y axis).This control was used to set the negative gate for PerCP. (b) Anti-CD45-PerCP isotype control ( $x$ axis) vs APC isotype control ( $y$ axis). This control was used to set the negative gate for APC. (c) Anti-pro-Col-l $\alpha$ ( $x$ axis) vs anti-CD45 ( $y$ axis) on PBMCs from a subject $>60$ years old. (d) Anti-CD34 ( $x$ axis) vs anti-CD14 ( $y$ axis) on the double-positive population seen in panel c. (e) Anti-pro-Col-l $\alpha$ ( $x$ axis) vs anti-CD45 ( $y$ axis) on PBMCs from a patient with SSc-ILD. (f) Anti-CD34 ( $x$ axis) vs anti-CD14 (y axis) on the double-positive population seen in panel e. (g-j) Comparison of CD34+ CD14- (g), CD14+ CD34 + (h), CD34$\mathrm{CD} 14+(\mathbf{i})$, and CD14-CD34- (j) populations in the pro-Col-l $\alpha^{+}$cells obtained from (left to right) subjects $>60$ years old $(n=10$, black bar) and those with SSc-ILD $\left(n=7\right.$, slanted bar). Data are expressed as mean \pm s.e.m. ${ }^{\star} P<0.05,{ }^{*} P<0.01$. 
fibrosis, ${ }^{38}$ pulmonary fibrosis, ${ }^{16,17,29}$ and asthma. ${ }^{39,40}$ Most of these studies have used the combination of CD45 and pro-Col-I $\alpha$ to identify these cells and have assumed them to be fibrocytes. However, a recent study demonstrates some overlap in the markers used to identify fibrocytes and particular macrophage subsets. ${ }^{35,41}$ Our data indicate that the blood of patients with SSc-ILD and healthy aged controls is enriched for collagen-producing cells. In the scleroderma patients, this increase seems to relate to an increase in fibrocytes (identified by the expression of CD45, CD34, and pro-collagen I), as well as an intermediate cell population characterized by the expression of CD45, CD14, CD34, and pro-collagen I. As CD34 is a marker of progenitor cells, these results may indicate either decreased terminal differentiation of fibrocytes in the SSc-ILD patients or an increase in the efflux of progenitor cells from the bone marrow. In contrast, in aged subjects, the increase in circulating $\mathrm{CD}_{4} 5^{+} /$pro-Col$\mathrm{I}^{+}$cells seems to result from increased collagen production by $\mathrm{CD} 14+$ monocytes as well as a population of $\mathrm{CD} 45^{+}$/ pro-Col- $\alpha^{+}$cells expressing neither CD34 nor CD14. Although the precise identity and significance of these cells in aging remains to be determined, the increased fibrocyte levels detected in our SSc-ILD patient cohort may promote lung remodeling by a number of mechanisms including direct matrix production, antigen presentation and immune stimulation, and cytokine and growth factor production. ${ }^{42}$ Alternately, the increase in fibrocytes observed in our SSc-ILD cohort may represent a host response to fibrosis and an attempt to normalize repair.

Alternatively, activated macrophages displaying high-level production of IL-10 and CCL1 $8^{43}$ have been found in the lungs of patients with SSc. ${ }^{43}$ Our data show that LPSstimulated monocytes from patients with SSc-ILD demonstrate enhanced CD163 expression, and increased CCL18 and IL-10 secretion when compared with monocytes from agematched normal controls, thus confirming the fibrogenic potential of this cell population. These findings also agree with a recent report that LPS-activated dendritic cells from patients with SSc produce greater levels of CCL18 and IL-10 in vitro. ${ }^{36}$ Although one recent report suggests that cultured fibrocytes can express $\mathrm{CD} 163,{ }^{35}$ the round rather than spindle-shaped morphology of CD163 + cells in our studies supports the contention that these cultured cells are macrophages. ${ }^{35}$ Owing to the evidence that circulating monocytes give rise to alveolar macrophages ${ }^{44}$ it is intriguing to find evidence for a fibrogenic phenotype within monocytes that is detectable before the entry of these cells into diseased lungs. This finding supports the idea that monocyte phenotypes may be pre-programmed to adopt their ultimate activation state, perhaps through genetic or epigenetic alterations in progenitor cells. It also is noteworthy that in both aged patients and in those with SSc-ILD, cultured monocytes adopt this phenotype in response to LPS, which stimulates the TLR4 receptor. ${ }^{23}$ These data suggest that the monocytes of these patients are inappropriately skewed toward an alternatively activated phenotype, which could account for both the propensity to develop fibrosis and the abnormalities in host defense that may be seen in both aged patients ${ }^{45}$ and in those with SSc-ILD. ${ }^{46}$

The 'type II hypothesis of fibrosis' posits that an imbalance between Th1 and Th2 cytokines alters tissue microenvironments toward a profibrotic phenotype ${ }^{47}$ and Th2 cytokines regulate the differentiation and activation of both fibrocytes ${ }^{48}$ and M2s. ${ }^{22}$ Indeed, we detected an increase in IL-10, MCP-1, IL-1 RA, and TNF- $\alpha$, as well as decreased M-CSF in the blood of patients with SSc-ILD when compared with both older and younger controls. This combination of cytokines may contribute to the increase in $\mathrm{CD} 34+$ fibrocyte numbers observed in the SSc-ILD group as well as to the increased CCL18 and IL-10 levels seen in response to LPS stimulation of SSc-ILD monocytes. In contrast, the blood of aged healthy controls contained increased IL-4, IL-10, IL-13, MCP-1, and CCL18, but decreased TNF- $\alpha$ when compared with young healthy controls. However, these mediators did not differ between aged subjects and those with SSc-ILD. Given the differences in $\mathrm{CD} 45^{+} /$pro-Col- $\mathrm{I} \alpha^{+}$cell phenotypes seen in our cohort, it is possible that this combination of cytokines may induce collagen expression in monocytes, but that IL-1 RA and TNF- $\alpha$ are required for the maintenance of CD34 expression. It also is possible that the increase in M-CSF detected in the aged controls compared with SSc-ILD subjects drives CD14 + cells away from the fibrocyte phenotype.

One particularly intriguing and unexpected finding concerns the age-dependent changes in the quantities of circulating $\mathrm{CD} 45^{+} /$pro-Col-I $\alpha^{+}$cells that we observed. Although age-related changes in monocyte quantity and activation, ${ }^{49}$ and blood levels of MCP- $1^{50}$ and IL- $13^{51}$ have been reported, to our knowledge these are the first data linking the accumulation or trafficking of collagen-expressing cells in the blood with normal aging. Our data show an increase in lymphocytes and monocytes in the aged population and a very strong association between this monocytosis and collagen production by CD14 + cells. It is possible that had we examined complete blood counts from these patients before Ficoll purification, the results would have differed, as the Ficoll-based cell separation can cause a variable loss of cells, ${ }^{52}$ or that our inclusion of healthy elderly subjects accounts for this increase in cell counts, as previous study has shown that leukocyte counts of aged and frail individuals are significantly lower than those of aged but healthy subjects. ${ }^{53}$ It also is possible that these findings result from the higher observed plasma levels of IL-4, IL-10, IL-13, CCL18, and MCP-1 in the blood of aged individuals. Given the limitations of clinical data, we also cannot rule out the possibility that these findings may be related to undiagnosed medical conditions, bone marrow abnormalities, or immunosenescence. On the based of these findings we suggest that circulating fibrocytes and collagen-producing monocytes may have an additional physiological role in the maintenance of tissue homeostasis during normal aging. 
In conclusion, these data strengthen the association between fibrocytes, alternatively activated macrophages, and SSc-ILD. The distinct profibrotic phenotype of circulating monocytes in SSc-ILD implies that abnormalities in differentiation, recruitment, trafficking, activation, and clearance of these cells may be important factors in the pathogenesis of lung fibrosis in this patient population.

\section{ACKNOWLEDGEMENT}

This work was supported in part by awards from the NIH (P30AR053495-01A1, K08 HL079066, UL1 RR024139, and N01 A150031) an Edward Mallinckrodt, Jr Scholar Award, funds from the Yale Department of Medicine, and Promedior, Inc. (all to ELH).

\section{DISCLOSURE/CONFLICT OF INTEREST}

LM is an employee of and RB is a member of the Scientific Advisory Board of Promedior, Inc. RB is a coinventor on a patent describing the therapeutic utility of fibrocytes.

1. Steen VD, Medsger TA. Changes in causes of death in systemic sclerosis, 1972-2002. Ann Rheum Dis 2007;66:940-944.

2. Tashkin DP, Elashoff R, Clements PJ, et al. Cyclophosphamide versus placebo in scleroderma lung disease. N Engl J Med 2006;354: 2655-2666.

3. D'Ovidio F, Singer LG, Hadjiliadis $D$, et al. Prevalence of gastroesophageal reflux in end-stage lung disease candidates for lung transplant. Ann Thorac Surg 2005;80:1254-1260.

4. D'Ovidio $F$, Mura $M$, Tsang $M$, et al. Bile acid aspiration and the development of bronchiolitis obliterans after lung transplantation. J Thorac Cardiovasc Surg 2005;129:1144-1152.

5. Abe R, Donnelly SC, Peng T, et al. Peripheral blood fibrocytes: differentiation pathway and migration to wound sites. J Immunol 2001;166:7556-7562.

6. Gordon S, Taylor PR. Monocyte and macrophage heterogeneity. Nat Rev Immunol 2005;5:953-964.

7. Katebi M, Fernandez $\mathrm{P}$, Chan ES, et al. Adenosine A2A receptor blockade or deletion diminishes fibrocyte accumulation in the skin in a murine model of scleroderma, bleomycin-induced fibrosis. Inflammation 2008;31:299-303.

8. Quan TE, Cowper S, Wu SP, et al. Circulating fibrocytes: collagen-secreting cells of the peripheral blood. Int J Biochem Cell Biol 2004;36:598-606.

9. Ihn H. [Systemic sclerosis]. Nippon Rinsho 2009;67:519-522.

10. Niedermeier M, Reich B, Gomez M, et al. CD4+ T cells control the differentiatin of Gr1+ monocytes into fibrocytes. Proc Natl Acad Sci USA 2009;106:17892-17897.

11. Bucala R, Spiegel LA, Chesney J, et al. Circulating fibrocytes define a new leukocyte subpopulation that mediates tissue repair. Mol Med 1994;1:71-81.

12. Sakai $N$, Wada $T$, Yokoyama $H$, et al. Secondary lymphoid tissue chemokine (SLC/CCL21)/CCR7 signaling regulates fibrocytes in renal fibrosis. Proc Natl Acad Sci USA 2006;103:14098-14103.

13. Kisseleva $\mathrm{T}$, Uchinami H, Feirt N, et al. Bone marrow-derived fibrocytes participate in pathogenesis of liver fibrosis. J Hepatol 2006;45:429-438.

14. Bellini A, Mattoli $S$. The role of the fibrocyte, a bone marrow-derived mesenchymal progenitor, in reactive and reparative fibroses. Lab Invest 2007;87:858-870.

15. Vakil V, Sung JJ, Piecychna $M$, et al. Gadolinium-containing magnetic resonance image contrast agent promotes fibrocyte differentiation. J Magn Reson Imaging 2009;30:1284-1288.

16. Moeller A, Gilpin SE, Ask K, et al. Circulating fibrocytes are an indicator for poor prognosis in idiopathic pulmonary fibrosis. Am J Respir Crit Care Med 2009;179:588-594.

17. Andersson-Sjoland A, de Alba CG, Nihlberg K, et al. Fibrocytes are a potential source of lung fibroblasts in idiopathic pulmonary fibrosis. Int J Biochem Cell Biol 2008:40:2129-2140.

18. Mehrad B, Burdick MD, Strieter RM. Fibrocyte CXCR4 regulation as a therapeutic target in pulmonary fibrosis. Int J Biochem Cell Biol 2009;41:1708-1718.
19. Aiba S, Tabata N, Ohtani $\mathrm{H}$, et al. CD34+ spindle-shaped cells selectively disappear from the skin lesion of scleroderma. Arch Dermatol 1994;130:593-597.

20. Duffield JS, Forbes SJ, Constandinou CM, et al. Selective depletion of macrophages reveals distinct, opposing roles during liver injury and repair. J Clin Invest 2005;115:56-65.

21. Martinez FO, Sica A, Mantovani A, et al. Macrophage activation and polarization. Front Biosci 2008;13:453-461.

22. Martinez FO, Gordon S, Locati M, et al. Transcriptional profiling of the human monocyte-to-macrophage differentiation and polarization: new molecules and patterns of gene expression. J Immunol 2006;177:7303-7311.

23. Prasse A, Germann M, Pechkovsky DV, et al. IL-10-producing monocytes differentiate to alternatively activated macrophages and are increased in atopic patients. J Allergy Clin Immunol 2007:119:464-471.

24. Duffield JS. The inflammatory macrophage: a story of Jekyll and Hyde. Clin Sci (Lond) 2003;104:27-38.

25. Hieshima K, Imai T, Baba M, et al. A novel human CC chemokine PARC that is most homologous to macrophage-inflammatory protein-1 alpha/LD78 alpha and chemotactic for T lymphocytes, but not for monocytes. J Immunol 1997;159:1140-1149.

26. Prasse A, Pechkovsky DV, Toews GB, et al. A vicious circle of alveolar macrophages and fibroblasts perpetuates pulmonary fibrosis via CCL18. Am J Respir Crit Care Med 2006;173: 781-792.

27. Meneghin A, Hogaboam CM. Infectious disease, the innate immune response, and fibrosis. J Clin Invest 2007;117:530-538.

28. Prasse A, Pechkovsky DV, Toews GB, et al. CCL18 as an indicator of pulmonary fibrotic activity in idiopathic interstitial pneumonias and systemic sclerosis. Arthritis Rheum 2007;56:1685-1693.

29. Mehrad B, Burdick MD, Zisman DA, et al. Circulating peripheral blood fibrocytes in human fibrotic interstitial lung disease. Biochem Biophys Res Commun 2007;353:104-108.

30. Ding $Y$, Boguslawski EA, Berghuis BD, et al. Mitogen-activated protein kinase kinase signaling promotes growth and vascularization of fibrosarcoma. Mol Cancer Ther 2008;7:648-658.

31. Niedermeier M, Reich B, Gomez MR, et al. CD4+ T cells control the differentiation of Gr1+ monocytes into fibrocytes. Proc Natl Acad Sci USA 2009;106:17892-17897.

32. Chesney J, Metz C, Stavitsky AB, et al. Regulated production of type I collagen and inflammatory cytokines by peripheral blood fibrocytes. J Immunol 1998;160:419-425.

33. Higashi-Kuwata N, Makino $\mathrm{T}$, Inoue $\mathrm{Y}$, et al. Alternatively activated macrophages (M2 macrophages) in the skin of patient with localized scleroderma. Exp Dermatol 2009;18:727-729.

34. Moriyama $\mathrm{H}$, Kobayashi $\mathrm{M}$, Takada $\mathrm{T}$, et al. Two-dimensional analysis of elements and mononuclear cells in hard metal lung disease. Am J Respir Crit Care Med 2007;176:70-77.

35. Pilling $D$, Fan $T$, Huang $D$, et al. Identification of markers that !distinguish monocyte-derived fibrocytes from monocytes, macrophages, and fibroblasts. PLoS One 2009;4:e7475.

36. van Lieshout AW, Vonk MC, Bredie SJ, et al. Enhanced interleukin-10 production by dendritic cells upon stimulation with Toll-like receptor 4 agonists in systemic sclerosis that is possibly implicated in CCL18 secretion. Scand J Rheumatol 2009;4:1-9.

37. Lee CG, Homer RJ, Cohn L, et al. Transgenic overexpression of interleukin (IL)-10 in the lung causes mucus metaplasia, tissue inflammation, and airway remodeling via IL-13-dependent and -independent pathways. J Biol Chem 2002;277:35466-35474.

38. Bucala R. Circulating fibrocytes: cellular basis for NSF. J Am Coll Radiol 2008;5:36-39.

39. Schmidt M, Sun G, Stacey MA, et al. Identification of circulating fibrocytes as precursors of bronchial myofibroblasts in asthma. $\mathrm{J}$ Immunol 2003:171:380-389.

40. Wang $\mathrm{CH}$, Huang $\mathrm{CD}$, Lin $\mathrm{HC}$, et al. Increased circulating fibrocytes in asthma with chronic airflow obstruction. Am J Respir Crit Care Med 2008;178:583-591.

41. Schnoor M, Cullen P, Lorkowski J, et al. Production of type VI collagen by human macrophages: a new dimension in macrophage functional heterogeneity. J Immunol 2008;180:5707-5719.

42. Gomperts BN, Strieter RM. Fibrocytes in lung disease. J Leukoc Biol 2007;82:449-456. 
43. Luzina IG, Atamas SP, Wise R, et al. Gene expression in bronchoalveolar lavage cells from scleroderma patients. Am J Respir Cell Mol Biol 2002;26:549-557.

44. Everhart MB, Han W, Parman KS, et al. Intratracheal administration of liposomal clodronate accelerates alveolar macrophage reconstitution following fetal liver transplantation. J Leukoc Biol 2005;77:173-180.

45. Caruso C, Buffa S, Candore G, et al. Mechanisms of immunosenescence. Immun Ageing 2009;6:10.

46. Juarez M, Misischia R, Alarcon GS. Infections in systemic connective tissue diseases: systemic lupus erythematosus, scleroderma, and polymyositis/ dermatomyositis. Rheum Dis Clin North Am 2003;29:163-184.

47. Sime PJ, O'Reilly KM. Fibrosis of the lung and other tissues: new concepts in pathogenesis and treatment. Clin Immunol 2001;99:308-319.

48. Shao DD, Suresh R, Vakil V, et al. Pivotal Advance: Th-1 cytokines inhibit, and Th-2 cytokines promote fibrocyte differentiation. J Leukoc Biol 2008:83:1323-1333.
49. Sadeghi HM, Schnelle JF, Thoma JK, et al. Phenotypic and functional characteristics of circulating monocytes of elderly persons.

Exp Gerontol 1999;34:959-970.

50. Gerli R, Monti D, Bistoni O, et al. Chemokines, sTNF-Rs and sCD30 serum levels in healthy aged people and centenarians. Mech Ageing Dev 2000;121:37-46.

51. Shearer GM. Th1/Th2 changes in aging. Mech Ageing Dev 1997;94: $1-5$.

52. Hokland $P$, Heron I. The Isopaque-Ficoll method re-evaluated: selective loss of autologous rosette-forming lymphocytes during isolation of mononuclear cells from human peripheral blood. Scand J Immunol 1980;11:353-356.

53. Kapasi ZF, Ouslander JG, Schnelle JF, et al. Effects of an exercise intervention on immunologic parameters in frail elderly nursing home residents. J Gerontol A Biol Sci Med Sci 2003;58: 636-643. 